\title{
16 Governing critical infrastructure in digital futures
}

\author{
Louis Klein
}

\section{Critical infrastructure}

Today, we are only a few days away from civil war, say the critical infrastructure providers. Imagine a blackout, no electricity, nowhere in the entire grid. Moreover, the electricity does not come back. A few backup generators will kick in and sustain an emergency mode, for a few days, especially for hospitals, police and army, and some of the rich. Private households seek for a safety net. People run for food and petrol. But stocks will deplete soon. The cooling chain breaks down. Frozen and fresh food turns bad. After three days the shelves are empty, transportation breaks down, and communications fade out. The civil order starts to crumble as people run out of food with little or no information about what is happening. Rumours spread and anxieties grow into panic. Scuffles grow into fights. While in hospitals, patients who cannot be sustained must die. The first gun is fired.

Modern societies are far more vulnerable as the occasional hacker attacks suggest. If critical infrastructure breaks down, society collapses. An electricity black-out maybe just an example a critical infrastructure breakdown, However, in modern society energy is vital for almost everything. Moreover, the more developed a society, the harder the blow. Hence, critical infrastructure is a major concern of institutional and organisational risk management. Yet, there is a trade-off between criticality and efficiency. The more efficient a system, the lower is its resilience, and the higher is its criticality (Klein 2018a). So, if we want to optimise resource efficiency, we need to keep more than a watchful eye on criticality. However, our appetite for energy is limitless. The growth curves described in the so-called Great Acceleration (Colvile 2016; McNeill \& Engelke 2014) are exponential. We may debate if the resources we are consuming are three, six or seven times beyond the regenerative capacity of our planet. This debate is futile. The challenge at hand is far beyond incremental solutions. It is a question of bold systems change.

There is no right life in the wrong one, said the German philosopher and founder of the Critical School, Theodor W. Adorno (1951). In a globalised world, in the age of the Anthropocene, there are no sustainable pockets of 
happiness. The dynamic interdependencies of the living world do not allow for small, isolated solutions. Facing the challenges of the Anthropocene in the 21 st century, we need to acknowledge that despite campaigns like the UN Sustainable Development Goals, our current debates are missing the point in so many ways. Neither the resource challenge nor the security and resilience of critical infrastructure can be treated and solved in isolation. These challenges go deep and address the very fabric of our societies and the very thinking that brought about those social systems that characterise western modernity. Everything needs to be challenged. Building on Albert Einstein's famous quote that the thinking that brought about the problems will not be thinking that yields the solutions, we need to start looking for new thinking, for an epistemological turn towards Anthropocene Thinking that puts an end to the paradigms of modernity and take it from there.

First, we need to understand our understanding, understand our thinking and the regimes we use to govern (Foerster 2002). We need to acknowledge the ruling matrix of epistemological propositions that determines our worldview. We will learn that it is us who conceived and created the reality we live in. Moreover, advanced technology is only able to support us as far as our ideas can provide for it. We need to understand that there is more than one future (Poli 2011) and that systems change is not a question of incremental project management, but a matter of mind shift and leverage points (Klein 2019). We need to understand that competition yields perverse incentives and scarcity, and that smart rules govern serious games (Klein 2018b) which can manifest the common good not only respecting the sustainability of our planet but contributing to a thrivable living world.

This kind of systems change will allow for sustainable energy regimes that do not deplete resources but grows them. It will enable us to translate sustainable energy regimes into critical infrastructure that supports this sustainability, that meets the requirements of robustness, resilience, and anti-fragility, and performs as effective as efficient. We may in the age of big data, digital transformation, and artificial intelligence (AI) conceive of distributed autonomous infrastructure systems which reliably harvest and distribute renewable energy serving the common good while sustaining a thrivable planet. Technology, however, comes last. First, we need to understand understanding and allow for another thinking.

\section{Anthropocene thinking}

We live in a post-truth society not because our political world is full of lies but because we live in a VUCA, a volatile, uncertain, complex, and ambiguous, world which needs more than truth. We need volatility sciences, uncertainty sciences, complexity sciences, and ambiguity sciences. If we want to meet the challenges of the Anthropocene in the 21st century, we need thinking beyond the reductionist paradigms of modernity. Anthropocene thinking (Klein 2018c) identifies three candidates contributing to the necessary epistemological turn in 
the current scientific debates. First, systems sciences and cybernetics; second, integral theory; and third, theories of resonance.

Systems sciences and cybernetics are certainly the backbones of Anthropocene thinking. Systems sciences and cybernetics and later chaos and complexity sciences went into the challenge of dependent variables, feedback loops, path dependency, the power of context, the sensitivity to initial conditions and emergence (Boulton, Allen, and Bowman 2015). They can model and simulate system dynamics and explore the future implications of any complex system (Forrester 1968). The Report to the Club of Rome about the limits of growth is, undoubtedly, a hallmark of systems sciences and cybernetics (Meadows et al. 1972). Also, the Operations Room to govern the entire economy based on the Viable Systems Model in Allende's Chile in 1973 led by the cybernetician Stafford Beer made it into the pop culture of digital natives (Medina 2011). The relationship of systems sciences and cybernetics to modern sciences is like the relationship of quantum mechanics and relativity theory to classical mechanics. Modern sciences, as well as classical mechanics, are simple, limited cases of the broader theory.

Integral theory is the most popular of the three candidates. It became so popular for addressing individual cognitive and moral development that a plethora of self-help and self-improvement movements highjacked it for their cause. Seen from the perspective of Anthropocene thinking, it is the research on individual and collective development as well as social integration that makes it remarkable (McIntosh 2007; Loevinger 1987). It fills the blind spot systems sciences and cybernetics have with respect of the conditio humana. The inevitability of the living body, the conscious self and the social others need to be addressed to relate to human beings and not only to systems (Klein 2012). Integral theory provides this and opens perspectives of alternative developments and different processes of civilisation.

Theories of resonance are new and ancient at the same time. Theories of resonance are new because only lately, the focus broadened from a specific psychological theory to entire social systems (Rosa 2016). They suggest harmonious resonance as the critical criteria for human wellbeing addressing the three inevitable levels of the conditio humana. We can be in tune with your living body, your conscious self, and the social others. Communications, groups, and societies can be resonant and in tune. Yet, resonance reaches far beyond the human scale into nature resonating with the totality of the living world as described in the popular Gaia hypothesis (Margulis 1998; Lovelock 1979).

Resonance is a universal phenomenon that travels from the very elementary processes of quantum mechanics via the self-awareness of the human being to the harmonic relationships that rule the stars and the constellation of the cosmos. Looking for resonance allows us to go back in time, and therefore theories of resonance can be considered to be rather acient, before the Enlightenment, before the Renaissance and even before the Axial Age (8th to the 3rd century BCE). In the Vedic scripts of ancient India (1700 to 1100 $\mathrm{BCE})$, meaning was attributed to sound and colour. In physical terms, 
meaning was attributed to a frequency of soundwaves and light waves. This scientific insight suggests that meaning can be processed in the form of those frequencies. Peculiar as it occurs, we have an intuition for this when we speak and communicate. We process meaning in the basic form of frequencies based on resonance and call it words, sentences, stories, and narratives. With theories of resonance, we look at an entirely different paradigm which may revolutionise even our understanding of quantum computing moving away from digital logic towards the computable resonance.

Theories of resonance specify the quality of integration while integral theory addresses the scale and coherence of integration. This combination of integral theory and theories of resonance bridges a scientific understanding of matter, energy, and life in the form of critical spirituality to Daoist traditions (Ames \& Hall 2003) and recent developments of Apithology, the discipline that studies the generative causes of health and wellness in living systems (Varey 2008). Both are approaching health and well-being from the larger picture of the totality of the living world, both arriving at what currently features as One Health regarding the future of medicine and healthcare, which argues that there cannot be individual health on a sick planet (Zinsstag et al. 2015; Atlas \& Maloy 2014).

\section{Governing good governance}

Anthropocene thinking enlarges our understanding of governance. If we look at the different governments and regimes in the world and even when we look at western democracies only, we see plenty of versions featured under the same headline. We may use the explanation that different cultures and different values yield different regimes and various versions of democracy, however, this remains on the very surface. Western democracies, for example, are all founded on a set of the same three fundamental values. liberté, égalité, fraternité is the triad of the French revolution. The Germans' national anthem speaks of Einigkeit und Recht und Freiheit. It is personal freedom, equality before the law and societal solidarity which address the foundation of a desirable society or to be more precise, as the foundation of the governance of a desirable society. A theory of civilisation based on integral theory argues that there are three levels of societal maturity combined in this triad of social integration. First, there is the level of law and order which overcomes the earlier level of fight and force. With an accepted rule of law, a society can shield itself against civil war and the law of the jungle. It usually comes with a strong hierarchy and negative sanctions. A mighty ruler owning the monopoly of the use of forces will punish those who violate the rules. Second, there is the level of competition and personal freedom to pursue one's happiness participating in this competition.

Competition allows for personal ambition and fuels the individual motivation to go the legendary extra mile. The social integration mechanism is an investment and return. Those who do more deserve more. This leads to meritocracies which come at the price that those at the bottom are not simply 
unlucky but deserve to have not. In its extreme form competition challenges the right to exist of those who do not, as we say, earn their living. The level of competition builds on the level of rules and regulations to be distinct to the law of the jungle. Third, there is a level of societal solidarity. A society can overcome competition and share what was achieved collectively with everybody. It is not a matter of redistributing individual crops. It is based on the ancient Greek insight, attributed to Aristotle, that the whole is more than the sum of its parts. Collectively we create value beyond the individual returns. This is more than value-added, it is something that, for the lack of a better word, could be called hypervalue (Klein 2017). A society can agree to tap into this hypervalue to mitigate the downside of competition, allowing for both the individual pursuit of happiness and societal solidarity. Hypervalue, in this sense, is the new commons which operate along the lines of agreement and sharing.

In contemporary western democracies, we see all three levels of social integration in place, the rule of law, competition, and societal solidarity. However, increased competition dominates and seems to be applied to almost all walks of life. It looks like a successful paradigm being overstretched to the extent that it yields the right opposite of what it intended (Kuhn 1962). Overstretched competition produces scarcity where there is none for the sake of profit. Integral theory looking into modes of social integration and levels of civilisation as well as systems sciences and cybernetics understanding the emergence and hypervalue provide an understanding that yields new options for good governance.

Context design and individual care lie at the heart of good governance. Understanding the power of context opens a new perspective on rules and regulations. It is a little bit like nudging individuals to do what is better for them (Thaler \& Sunstein 2008). The rules and regulations of social systems can also be seen as rules and regulations of serious games, one may be the economy the other politics and so forth. Games, however, have their own character. In the game Monopoly, for example, one player after the other goes bankrupted and drops out until only one player is left owning all the property and having all the money. Or there is a game like Settlers of Catan where all players stay in the game until the very end, rightfully hoping to win while the game unfolds, and the winner wins by a margin. Settlers of Catan was awarded game of the year in 1995 meeting all the criteria which make a good game. There is a lot to learn from game design for governing societies. Moreover, we can learn from systems sciences and cybernetics how the various serious games of society feed into each other.

\section{Choosing futures}

Meaning, said the German sociologist Niklas Luhmann, is the unity of the distinction between actuality and possibilities (1984). Psychic systems and social systems can relate to futures in the form of meaning. They need to do so 
to survive and sustain themselves. We think about futures routinely. However, we are matrix-bound. We can only see what our epistemological proposition allows us to see. If we want to overcome this, we need to challenge our matrix, and the easiest way to do so is to do this together. Exploring the unknown and conceiving of alternative futures scenarios can follow meaningful conversations and facilitating processes which overcome epistemological silos and embrace diversity (Bennett et al. 2016; Poli 2011). We cannot think what we cannot think, but what we could think is already present in the presence. It is in the various ingredients which makes the various futures distinct and unique.

Anticipation translates futures into practices and approaches feasibility (Poli 2010). The possibility of systems analytics in models and simulations adds to the possibility to explore the unknown and draw new maps which allow navigating a VUCA world. Shifting to Anthropocene Thinking allows to widen the view and to change the criteria of evaluation. If a futures scenario is functionally adequate, resilient, and sustainable if it is integrating into the broader scope of the living world and if it is improving resonance it is undoubtedly amongst the desirable futures to choose from.

In the 21st century, artificial intelligence (AI) is inevitable (Harari 2015; Brynjolfsson \& McAfee 2014). All futures of critical infrastructure we can think of will revolve around questions of AI. Nonetheless, technology comes last. Technology is an accelerator and supports to scale up, but technology is never a driver or a creator of momentum (Collins 2001). Someone builds technology and this someone as well as the building process is embedded in paradigms, in a specific tradition of theory and practice. In the end, technology is hardwired and coded thinking with all its propositions and dependencies. In this sense, technology manifests, accelerates, and scales a specific worldview and the according to social, cultural and political regimes (Marcuse 1964). And if we want to see systems change, we need to mind technology as the most conservative agent of the past.

Form follows function, is the modernist's building maxim. In the 21st century, we need to understand understanding first and acknowledge that function is already an embedded concept. Technology is never neutral. It is a manifestation of paradigms in use. So, if we use AI to upgrade what we have already, it will yield just more of the same. If we do not want more of the 3 same but systems change, we need to critically rethink what we have and conceive of desirable futures and their paradigmatic propositions. Then we can choose wisely before technology becomes hardwired and coded path dependency. This applies not only for critical infrastructure but also for AI itself (Minsky 2006). If you do not get what you wanted, you need to start all over again, if you still have the time given the challenges of the Anthropocene in the 21 st century.

Privatising critical infrastructures like electricity or water was a common practice praised in the late 20th century serving the paradigmatic idea of competition as a desirable mode of societal integration. The market 
competition was thought to serve the people better than rules and regulations of public administration. However, the nature of technology, for example, in energy production was not prone to competition but lead to oligopolies of a handful of players who could afford large investments in power plants and grids and time horizons of 30 to 40 years for a profitable return on investment. Moreover, moving critical infrastructure into competition produced perverse incentives. If a business model is set up to solve a social problem, it is set-up to benefit and profit from that problem. It needs the problem to exist and the greater the challenge, the more significant the profit. The conventional technology of energy production produces scarcity whenever demand rises. It does not support overcoming the problem.

The energy reaching the earth from the sun is abundant. Energy scarcity is not in the resource but in the infrastructure of producing and distributing energy. Changing the infrastructure of harvesting and allocating energy could create commons where energy is shared rather than sold. If we think of this scenario as a desirable future of critical infrastructure, we are looking at entirely different technological requirements, especially for the supporting AI.

We can think of commons, and we need to meet the criticality of energy infrastructure shielding us from the initial scenario of civil war. Critical infrastructure needs to be robust, resilient, and anti-fragile. The solution we see in organic life is next to optimal redundancy, not maximal effectiveness and efficiency. Redundancy, however, is the foe of profit. It became a word with a negative connotation. Yet, competition yields criticality, redundancy fosters sustainability.

Organic life's solution for safeguarding critical infrastructure is autonomous systems like respiration, blood circulation, the lymph system to name but a few. Hence, moving critical infrastructure away from competition does not mean to subdue to rules and regulations of public administration but to move on to the autonomy of commons. If this sounds like science fiction it meets the requirements of exploring a desirable futures scenario very well. The responsible decision, however, lies in the presence.

\section{Desirable AI}

AI is matrix-bound and purpose-driven (Tegmark 2017). AI can be curious and self-learning. It is matrix-bound like any other technology. It depends on its epistemological and paradigmatic propositions. If it is coded in terms of law and order, it does rarely exceed the scope of a diligent expert system. But it can be coded following other modes of social integration supporting competition as well as commons. It depends on the purpose. AI is purposedriven. The purpose is a normative proposition balancing strategic and operative requirements, presence and future. Purpose provides orientation. Do we want to make a profit or overcome criticality? Are we want to benefit from scarcity or integrate sustainably into the realms of the living world? According to the criteria we choose we choose. 
AI can be curious and self-learning. However, this is where AI imposes another layer of complexity and adds to the gravity of technological choices. Curious and self-learning AI does not only accelerate and scale, but it also grows. The criteria which guide the technological choices will guide the curiosity and self-learning of the AI. If we choose the AI to support competition, it will consequently grow problems, produce scarcity, and deplete resources. It will not stop in optimising itself to do so. It will pursue effectiveness and efficiency, grow lean, eliminate redundancies, and inevitably foster criticality. It optimises what it was built for. AI can also realise and grow commons if we want. It can support a transition from competition to sharing, engaging in different measures and indicators for social integration and quality of life.

We can use the AI to support those serious games we want to play, the good games, like in the strategy games the games industry features since the early 1990s. The generation we call millennials learnt to view the world in this way and to navigate the complexity of the so-called virtual world with ease. They think of society as something that is or should be governed by smart algorithms like those well-designed computer games. They know that flow leads to epic wins and that this bears the potential to change the world (McGonigal 2012). The voice in the Fridays for Future protests that they do not see desirable futures in the current regimes of petty public administration and cut-throat competition. Any human-made system is only as strong as the supporting narrative is shared (Jorgensen \& Largacha-Martinez 2014; Boje 2001). What holds for the acceptance of a currency applies to organisations, institutions, and regimes as well. They start to understand that they can choose a more desirable future.

AI does not understand narratives. It 'thinks' fast, not slow (Kahneman 2011). It is operationally closed in its digital logic. It can evaluate quickly according to its digital coding, yet it does not rationalise. It does not process meaning. This holds for its curiosity as well as for its self-learning, at least as far as we can see today. However, it can be used to realise the design of autonomous systems in reference to the hierarchy of human needs (Maslow 1943) and the sequences of personality development (Loevinger 1987). The more basic the level of human needs and the level of personality development, the more AI can be supportive. The more advanced and sophisticated the level of human needs and the level of personality development, the more comprehensive the realms of personal freedom AI can grant.

\section{Beyond critical infrastructure}

Imagine a world where curious and self-learning AI serves to safeguards critical infrastructure. A world where the governance of energy, food and water is integrated into autonomous systems based on the logic of the commons, a world where the governance of health, transportation, security, and telecommunications furthers integration and resonance. The world would be safer 
and greener for a start. Physiological needs were met, and a lot of psychological stress was eased. There was more room for family and friends, more time for personality development towards empathy, respect, and appreciation, for creativity, spontaneity, and new goals.

2045 would neither be the year of the singularity nor the year of nightfall (Morris 2013). AI would have learnt to govern critical infrastructure according to criteria of functional adequacy integration and resonance. Truth would still be cherished, but it ceased to be the single, limiting source of legitimisation. Progress would connotate advances in personal development and civilisation rather than technological frenzies. We would relate to critical infrastructure as we relate to respiration and heartbeat. We know it is in place, we know it serves us but more than this we could gratefully forget and trust.

The Anthropocene could be the era where anthropocentrism could be overcome, where integration aimed at the largest relevant level, the level of Gaia, the level of all the life on earth (Latour 2015). It could be an era where resonance would not end with the human scale but explore what Gaia has to say and find our place on a thrivable planet.

A better world starts as an exploration of desirable futures. We can change the world. But understanding our understanding comes first. Challenging our epistemological propositions and worldviews makes sure that we get it right. Anthropocene thinking suggests a way to do so.

\section{References}

Adorno, T. (1951). Minima Moralia: Reflections on a Damaged Life (ed. 2006; E. F. N. Jephcott, Übers.). London: Verso.

Ames, R., and Hall, D. (2003). Dao De Jing: A Philosophical Translation (reprint). New York: Ballantine Books.

Atlas, R. M., and Maloy, S. (2014). One Health: People, Animals, and the Environment. Washington, DC: American Society for Microbiology.

Bennett, E. M., Solan, M., Biggs, R., McPhearson, T., Norström, A. V., Olsson, P., ... $\mathrm{Xu}, \mathrm{J}$. (2016). Bright Spots: Seeds of a Good Anthropocene. Frontiers in Ecology and the Environment, 14(8), 441-448. https://doi.org/10.1002/fee.1309.

Boje, D. M. (2001). Narrative Methods for Organizational \& Communication Research. Thousand Oaks, CA: Sage Publications.

Boulton, J. G., Allen, P. M., and Bowman, C. (2015). Embracing Complexity: Strategic Perspectives for an Age of Turbulence. Oxford: Oxford University Press.

Brynjolfsson, E., and McAfee, A. (2014). The Second Machine Age: Work, Progress, and Prosperity in a Time of Brilliant Technologies (reprint 2016). New York: W. W. Norton \& Company.

Collins, J. (2001). Good to Great: Why Some Companies Make the Leap ... And Others Don't. New York: HarperBusiness.

Colvile, R. (2016). The Great Acceleration: How the World is Getting Faster, Faster. London: Bloomsbury.

Foerster, H. von. (2002). Understanding Understanding: Essays on Cybernetics and Cognition. New York: Springer. 
Forrester, J. W. (1968). Principles of Systems (ed. 1973). Cambridge, MA: Wright-Allen. Harari, Y. N. (2015). Homo Deus: A Brief History of Tomorrow (ed. 2017). London: Vintage. Jorgensen, K. M., and Largacha-Martinez, C. (2014). Critical Narrative Inquiry: Storytelling, Sustainability and Power. New York: Nova Science Publishers.

Kahneman, D. (2011). Thinking, Fast and Slow. London: Penguin.

Klein, L. (2012). The Three Inevitabilities of Human Being. A Conceptual Hierarchy Model Approaching Social Complexity. Kybernetes, 41(7/8), 977-984.

Klein, L. (2017). Tapping into Hypervalue - Innovating Economic Policy. Accessed 9. Jan. 2018, von European School of Governance: A Closer Look website: https:// europeanschoolofgovernance.eu/tapping-into-hypervalue-innovating-economic-policy/.

Klein, L. (2018a). Business Excellence: Die Vielfalt erfolgreich managen. Wiesbaden: Springer Gabler.

Klein, L. (2018b). Governing the Serious Games of Society. Accessed 28. Dec. 2018, von European School of Governance: A Closer Look website: https://europeanschoolofgovernance.eu/ governing-the-serious-games-of-society/.

Klein, L. (2018c). Venturing Anthropocene Thinking. Accessed 28. Dec. 2018, von European School of Governance: A Closer Look website: https://europeanschoolofgovernance. eu/venturing-anthropocene-thinking/.

Klein, L. (2019). Systems Change Revisited. Systemic Change Journal, 2(1).

Kuhn, T. S. (1962). The Structure of Scientific Revolutions (2nd ed. 1970). Chicago, IL: The University of Chicago Press.

Latour, B. (2015). Facing Gaia: Eight Lectures on the New Climatic Regime (ed. 2017). Cambridge: Polity.

Loevinger, J. (1987). Paradigms of Personality. New York: W.H. Freeman and Company.

Lovelock, J. (1979). Gaia: A New Look at Life on Earth (reprint 2016). Oxford: Oxford University Press.

Luhmann, N. (1984). Social Systems (ed. 1996; J. Bednarz \& D. Baecker, Übers.). Stanford, CA: Stanford University Press.

Marcuse, H. (1964). One-Dimensional Man: Studies in the Ideology of Advanced Industrial Society (ed. 1991). Boston, MA: Beacon Press.

Margulis, L. (1998). Symbiotic Planet: A New Look at Evolution. New York: Basic Books.

Maslow, A. H. (1943). A Theory of Human Motivation. Psychological Review, 50(4), 370-396.

McGonigal, J. (2012). Reality is Broken: Why Games Make Us Better and How They Can Change the World. London: Vintage.

McIntosh, S. (2007). Integral Consciousness and the Future of Evolution. St. Paul, MN: Paragon House.

McNeill, J. R., and Engelke, P. (2016). The Great Acceleration: An Environmental History of the Anthropocene Since 1945. Cambridge, MA: Harvard University Press.

Meadows, D. H., Meadows, D. L., Randers, J., and Behrens III, William W. (1972). The Limits to Growth: A Report for the Club of Rome's Project on the Predicament of Mankind. New York: New American Library.

Medina, E. (2011). Cybernetic Revolutionaries. Technology and Politics in Allende's Chile. Cambridge, MA: MIT University Press.

Minsky, M. (2006). The Emotion Machine: Commonsense Thinking, Artificial Intelligence, and the Future of the Human Mind (reprint 2007). New York: Simon \& Schuster.

Morris, I. (2013). The Measure of Civilisation: The Story of Why the West Rules for Now. London: Profile Books. 


\section{Louis Klein}

Poli, R. (2010). The Many Aspects of Anticipation. Foresight, 12(3), 7-17. https://doi.org/ 10.1108/14636681011049839.

Poli, R. (2011). Steps Toward an Explicit Ontology of the Future. Journal of Futures Studies, 16(1), 67-78.

Rosa, H. (2016). Resonance: A Sociology of Our Relationship to the World (ed. 2019). Cambridge: Polity.

Tegmark, M. (2017). Life 3.0: Being Human in the Age of Artificial Intelligence (ed. 2018). London: Penguin.

Thaler, R. H., and Sunstein, C. R. (2008). Nudge: Improving Decisions About Health, Wealth, and Happiness (rev. ed. 2009). London: Penguin Books.

Varey, W. (2008). Apithology: An Emergent Continuum. Journal of Apithological Practice, $1(1), 1-7$.

Zinsstag, J., Schelling, E., Waltner-Toews, D., Whittaker, M., and Tanner, M. (2015). One Health: The Theory and Practice of Integrated Health Approaches. Wallingford: CABI Publishing. 